\title{
Studies of the origin of skin burns during electrocautery based on multi-component plasma fluid model
}

Received: 22 April, 2020

Accepted: 05 May, 2020

Published: 06 May, 2020

*Corresponding author: Marija Radmilović-Radjenović, Institute of Physics, University of Belgrade, Pregrevica 118, 11080 Belgrade, Serbia, E-mail:marija@ipb.ac.rs

Keywords: Electrocautery; Burns; Monopolar; Multicomponent

https://www. peertechz.com

Check for updates

\author{
Marija Radmilović-Radjenović* and Branislav Radjenović \\ Institute of Physics, University of Belgrade, Pregrevica 118, 11080 Belgrade, Serbia
}

\begin{abstract}
Background: Electrocautery and Argon Plasma Coagulation (APC) are modes of thermal tissue destruction frequently recognized as a less expensive alternative to laser therapy. However, there are certain safety challenges concerning the use of electrosurgery and burns are the most common. According data found in the literature, burns have accounted for $70 \%$ of the injuries during use of electrocautery. The risk of complications is often linked to the surgeon's fundamental knowledge of instruments, surgical technique, safe technical equipment, etc. This study is focusing on sparking enhanced burns as a complication of monopolar electrocautery.
\end{abstract}

Methods: The onset of sparking between cylinder-cone electrode arrangement has been studied by using software package COMSOL based on the multi-component plasma fluid model. The primary goal was to determine location where sparking starts as one of the extremely important factors for the formation of burns during electrocautery.

Results: Upon applying voltage, electrons are accelerated by the electric field and multiplied in cascade ionization leading to breakdown and consequently to sparking. For cylinder-cone electrode configuration, sparking occurs on the cone tip. Also, electrical sparks do not occur equally in both directions between active and passive electrodes bringing electrical asymmetries into consideration.

Conclusion: Results, presented here, can be very useful both for developing new instrument designs and surgeon's better understanding the effect of sparking on the human body in order to prevent complications of electrocautery procedures.

\section{Background}

The term electrocautery refers to procedure based on using the heat from an electric current to obtain a desired clinical effects [1-3]. The current density required for this procedure is realized by short electric sparks which take place at peak voltages of around $200 \mathrm{~V}$ between the electrode and tissue. Once gas is released through the catheter tip, it is ignited through electrical current and an arc is formed leading to the heat destruction and desiccation of the tissue [4]. Although electrocautery had been used for decades, mechanism of burns is poorly understood even in the present day representing an active area of research. Therefore, studies of breakdown enhanced burns can be critically important in clinician understanding what medical and surgical problems may be expected [5].
Cautery can be operated in a monopolar or bipolar configurations [6]. In monopolar configuration, the current passes from the active electrode through the tissue to a dispersive electrode as illustrated in Figure 1. The characteristics of the current flow affect the depth, speed and degree of tissue heating and determine the tissue results [7]. The main mechanism responsible for burns during electrosurgery is the electrical breakdown. Since there has never been a report of a fire with bipolar electrocautery, this study is referring to the mechanism that leads to burns in the use of monopolar electrocautery Figure 1.

The main mechanism beyond skin burns during electrocautery is the electrical breakdown of a gas producing a conductive channel of ionized gas through which a current passes [8]. The electrode shape, surface conditions and variety of involved processes objectively stipulate a number of 


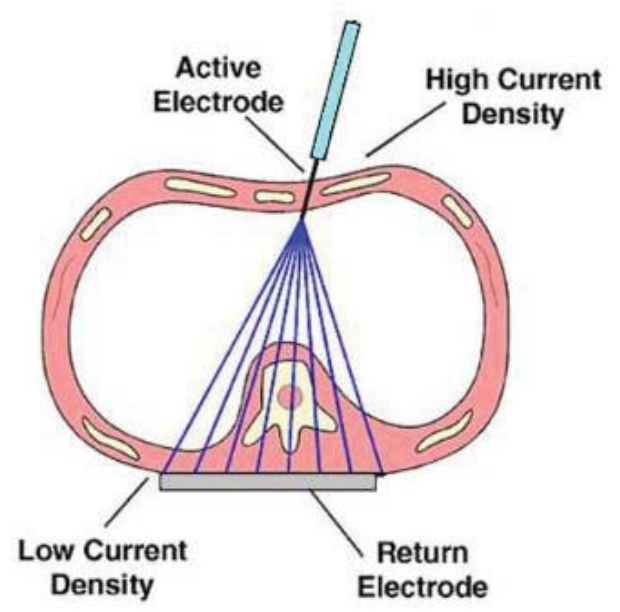

Figure 1: An electrosurgery circuit. Current flows through the tissue, generating heat within the tissue.

factors which may cause sparking during electrocautery and consequently severe burns. For estimating the effect of various factors computer modeling and simulations have proven to be very powerful tools that complement laboratory experiments and analytic models with a wide range of applications including medicine [9]. In this study, sparking between the cylinder-cone electrode configuration has been modeled by using software package COMSOL [10].

\section{Method}

The onset of the sparking during alectrocautery has been studied using software package COMSOL based on the multi-component plasma fluid model described in details in numerous publications [11-13]. COMSOL Multiphysics modeling environment includes all of the functionality of the Direct Current (DC) discharge and Capacitively Coupled Plasma (CCP) interfaces. One of the most important steps in finite element calculations is the meshing i.e. volume separation into a number of smaller elements affecting the computational time and accuracy of the obtained results [14]. Since studied systems have axial symmetry, we have used triangular mesh an extra fine element size as a quick and simple way to obtain meshes of high element quality that cover almost the whole geometry. For boundaries, however, 4-layers of qudrilateral elements are used. Calculations were performed for argon discharges with the focus on determination of the locations where sparking stars as very important factor in generation of the electrical burns during monopolar electrosurgery.

\section{Results}

The electric potential at the initial time (without plasma) in the case of cylinder-cone electrode arrangements are displayed in Figure 2. Upon applying voltage, electron density starts to change results in sparking on the cone tip as illustrated in Figures 3a,b shows temperature distribution between the electrodes at the bringing of sparking. Locations where sparking takes place in the case of the positive and negative cycles are illustrated in Figure 4. In both cases, electric field is neither uniform nor symmetrical and not affected by the presence of an organic tissue as concluded in ref. [15].

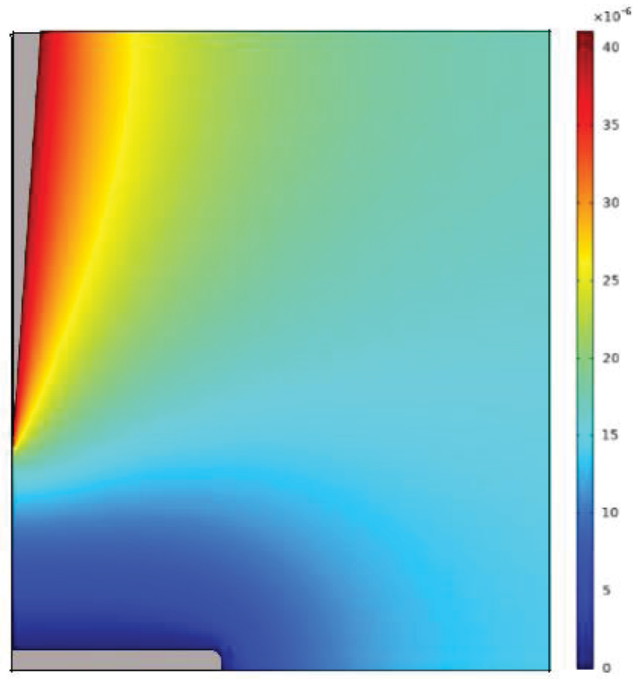

Figure 2: Electrical potential at the initial time $(t=0)$ for the electrode arrangements composed of cylinder-cone electrodes.
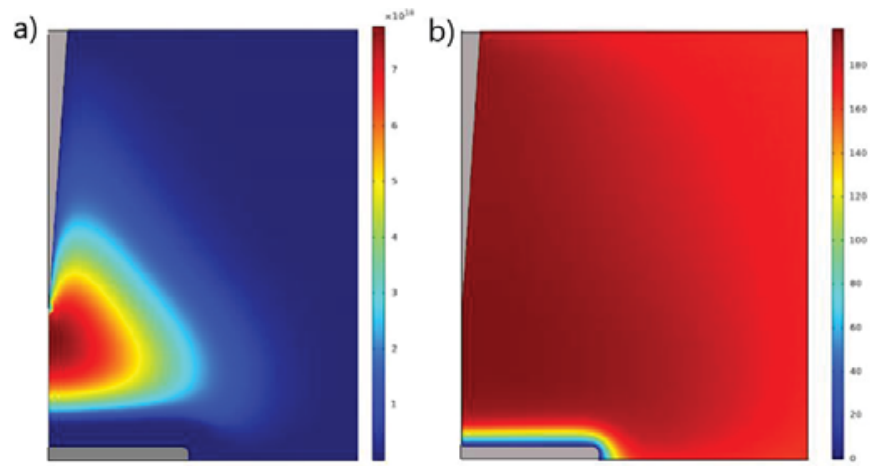

Figure 3: a) The electron density and b) temperature between the cylinder-cone electrodes at the moment of the onset of sparking.
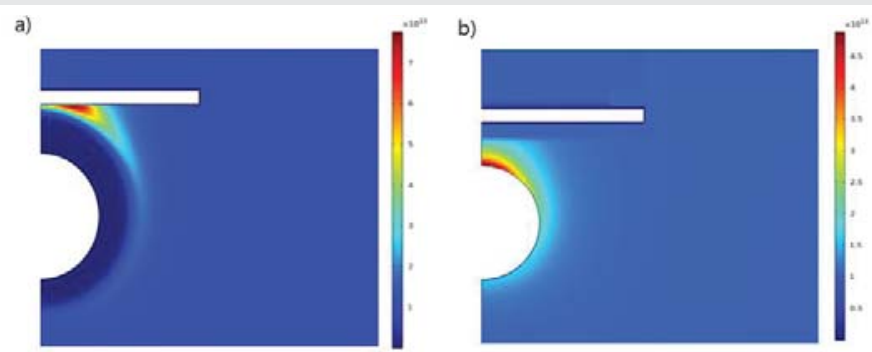

Figure 4: Sparking occuring between spherical metallic electrode and the meta plate which is: a) positive and b) negative.

\section{Conclusions}

This paper is dealing with electrosurgical spark as a main mechanism responsible for the delivery of energy to the tissue causing burns. Studies were accomplished using multi-component fluid model solved by the finite element method and implemented in the COMSOL softwer package. It was shown that the electrical sparks appear on the cone tip. Furthermore, sparking does not occur equally in both directions between active and passive electrodes introducing electrical asymmetries a consequence of the non symmetry of the electric field generated between them. Analysis of the obtained simulation results allow us to conclude that it is easier 
to produce a spark when the spherical electrode is negatively polarized. Small contact areas between the electrode and tissue generate quick, intense heating due to the high current density. On the other hand, the same power and larger contact areas lead to slower and weaker heating. Since the asymmetry is the cause of undesirable DC burns and the conformity process does not consider the sparking phenomena, the certification process at this class of equipment have to be improved. Actually, results presented here, could be very useful for in understanding the offset of skin burns needed to ensure patient safety.

\section{Acknowledgement}

The authors acknowledge funding provided by the Institute of Physics Belgrade, through the grant by the Ministry of Education, Science and Technological Development of the Republic of Serbia.

\section{References}

1. Prakash LD, Balaji N, Kumar SS, Kate V (2015) Comparison of electrocautery incision with scalpel incision in midline abdominal surgery-A double blind randomized controlled trial. Int J Surg 19: 78-82. Link: https://bit.ly/2L12En8

2. Ismail A, Abushouk Al, Elmaraezy A, Menshawy A, Menshawy E, et al. (2017) Cutting electrocautery versus scalpel for surgical incisions: a systematic review and meta-analysis. J Surg Res 220: 147-163. Link: https://bit.ly/2zfLkrJ

3. Bastianpillai J, Saxby C, Coyle P, Armstrong A, Mohamid W, et al. (2019) Evaluating nasal cautery techniques in epistaxis. J Laryngol Otol 133: 923927. Link: https://bit.ly/2YAQPMA

4. Saaiq M, Zaib S, Ahmad S (2012) Electrocautery burns: experience with three cases and review of literature. Ann Burns Fire Disasters 25: 203-206. Link: https://bit.ly/2SBhaWJ

5. Schneider B, Abatti PJ (2008) Electrical characteristics of the sparks produced by electrosurgical devices. IEEE Trans Biomed Eng 55: 589-593. Link: https://bit.ly/2SCSNIh

6. Tammam AE, Ahmed HH, Abdella AH, Taha SA (2015) Comparative Study between Monopolar Electrodes and Bipolar Electrodes in Hysteroscopic Surgery. J Clin Diagn Res 9: QC11-QC13. Link: https://bit.ly/2W6F9zW

7. Lee J, Cho JR, Kim MH, Oh HK, Kim DW, et al. (2020) Surgical outcomes according to the type of monopolar electrocautery device used in laparoscopic surgery for right colon cancer: a comparison of endo-hook versus endoshears. Surg Endosc 34: 1070-1076. Link: https://bit.ly/2yi3xVL

8. Grimnes S (1983) Dielectric breakdown of human skin in vivo. Med Biol Eng Comp 21: 379-381. Link: https://bit.ly/2L3aWuN

9. Lin CL, Lan GJ (2018) A computational approach to investigate optimal cutting speed configurations in rotational needle biopsy cutting soft tissue. Comput Methods Biomech Biomed Engin 21: 84-83. Link: https://bit.ly/2zSueR4

10. COMSOL Multiphysics. Link: https://bit.ly/3c5avMv

11. Wang MH, Chang WH (2015) Effect of Electrode Shape on Impedance of Single HeLa Cell: A COMSOL Simulation. BioMed Res Int 205: 871603. Link: https://bit.ly/3diEwZo

12. Alkaabi AK, King JC (2019) Benchmarking COMSOL Multiphysics SingleSubchannel Thermal-Hydraulic Analysis of a TRIGA Reactor with RELAP5 Results and Experimental Data. Sci Techn Nuclear Installation 2019: 4375782 Link: https://bit.ly/2SEp7ui

13. Radmilović-Radjenović M, Radjenović D, Radjenović B (2019) Simulation studies of the electrode configuration effect on the breakdown phenomenon. Int J Adv Res Comput Sci Electronic Eng 8: 68-72. Link: https://bit.ly/2Wrb9wZ

14. Ostroverkhov EV, Denisov VV, Lopatin IV, Koval NN (2018) Effect of the mesh emission electrode shape on the distribution of the plasma density generated in the working chamber. J Phys Conf Ser 1115: 032012. Link: https://bit.ly/2z6b21X

15. Dias EJ, Schneider BJ, Ribeiro E (2019) On the origin of skin burns and neuromuscular electrical stimulation as a consequence of electrosurgical procedures. Research Biom Eng 35: 111-122. Link: https://bit.ly/2WtBcnq

Peertechz journals wishes everlasting success in your every endeavours.

Copyright: @ 2020 Radjenović MR, et al. This is an open-access article distributed under the terms of the Creative Commons Attribution License, which permits unrestricted use, distribution, and reproduction in any medium, provided the original author and source are credited. 